\title{
Robotic Telescopes and Student Research in the School Curriculum around the OECD countries
}

Saeed Salimpour ${ }^{1 *}$, Sophie Bartlett ${ }^{2}$, Michael T. Fitzgerald ${ }^{3}$, K. Ross Cutts ${ }^{4}$, C. Renee James ${ }^{5}$, Scott Miller ${ }^{5}$, Lena Danaia ${ }^{6}$, Sergio Cabezon ${ }^{7}$, Michel Faye ${ }^{8}$, Cyrille Baudouin ${ }^{9}$, Diana

Birkenbauma $^{10}$, Sara Anjos ${ }^{11,12,13}$, Quixan Wu ${ }^{14}$, Hye-eu Chu ${ }^{15}$, Eileen Slater ${ }^{3}$

\begin{abstract}
The aim of this paper is to explore the presence and possible incorporation of inquiry-based learning approaches using Robotic Telescopes and Student Research in the regular science curriculum. This study uses preliminary findings from an extensive ongoing study, which is currently reviewing the extent of astronomy content in the school curriculum of the 35 member countries from the OECD in addition to two emerging nations in modern astronomy - China and South Africa, which are not part of the OECD. Analysis of curriculum documents from 28 OECD countries, including China and South Africa, reveals that although there is a prevalence of astronomy related content in most grades, incorporating Robotic Telescopes and Student Research into the regular science curriculum is limited by two interdependent factors. Firstly, the majority of curricula introduce astronomy-related concepts through a descriptive lens, with a focus on the "what?", rather than the "how?" or "why?". Secondly, astronomy in comparison to other topics gets very little time allocation. Robotic Telescopes provide teachers with enormous potential to teach students not only topics related to science, but also to afford students the opportunity to engage in "authentic science". Thus, it is vital for the members of the astronomy community to play a greater role in the development of curricula.
\end{abstract}

\section{Keywords}

Astronomy Curriculum; OECD; Robotic Telescopes; Student Astronomy Research

${ }^{1}$ Deakin University, Burwood, Victoria, Australia

${ }^{2}$ Cardiff University/Faulkes Telescope Project, Cardiff, Wales, United Kingdom

${ }^{3}$ Edith Cowan University, Edith Cowan Institute for Education Research, Western Australia, Australia

${ }^{4}$ St. Paul's Grammar School, New South Wales, Australia

${ }^{5}$ Sam Houston State University, Huntsville, TX, USA

${ }^{6}$ Charles Sturt University, New South Wales, Australia

${ }^{7}$ AUI/NRAO

${ }^{8}$ France Hands-On universe/Lousi le Grand High School, Paris, France

${ }^{9}$ Aix Marseille University, Marseille, France

${ }^{10}$ Jelgavas Vakara Vidusskola, Latvia

${ }^{11}$ NUCLIO - Núcleo Interactivo de Astronomia, Portugal

${ }^{12}$ Centro de Estudos Comunicação e Sociedade (CECS), University of Minho

${ }^{13}$ PLOAD (Portuguese Language Office of Astronomy for Development)

${ }^{14}$ Hangzhou No. 14 High School, Hangzhou, China

${ }^{15}$ Macquarie University, New South Wales, Australia

*Corresponding author: astrophysics@saeedsalimpour.com

\section{Introduction}

Inquiry-based learning (IBL), which is based on the philosophies of the constructivist movement (Dewey (1938); Bruner (1961); Vygotsky et al.
(1962), Vygotsky (1978)), has enjoyed widespread popularity in recent years. IBL also encompasses the interrelated notions of authentic science experiences (van Eijck and Roth, 2009), and authentic inquiry (Sarkar and Frazier (2008); see 
talk by Mary Dussault, RTSRE 2017). These notions of "inquiry" and "authenticity" are aimed at making the learning experience relevant and real, whilst trying to emulate, within constraints, "real-life" scientific investigation (Chinn and Hmelo-Silver, 2002). Unfortunately, some teachers lack the real-world scientific research skills (Buxner, 2014) needed to be able to nurture this in the classroom. Often teachers emphasize that science follows a linear step-by-step procedure, from hypothesis to conclusion. Scientists know all too well that this could not be further from the truth. Scientific investigation and research is filled with moments of serendipity and uncertainty. This notion was highlighted in the talk by Richard Berry at the RTSRE Conference 2017.

It should be noted, however, that teachers are restricted by time (McKinnon 2017, personal communication). The daily administrative responsibilities of teaching (at least in Australia and the UK) prevent most teachers from "exploring" topics, except for those mandated by the curriculum.

On the one hand, we have a seemingly rigid curriculum - the "Prime Directive" - which teachers are mandated to follow and "tick the boxes". On the other hand, we have technology that affords students the opportunity to experience "authentic" research. Some teachers would argue that the curriculum is too rigid and descriptive to allow exploration, whilst others would state that IBL requires time and may not be suited to all students (Fitzgerald et al., 2017).

This paper is part of an extensive ongoing study, which is currently reviewing the extent of astronomy in the school curriculum within the OECD countries, including China and South Africa (Salimpour et al. 2018, in prep.). China and South Africa despite not being members of the OECD, were included in this study given that they are becoming major players in the field of modern astronomy given large-scale projects like the Square Kilometre Array (SKA, South Africa) and the Five-hundred-meter Aperture Spherical radio Telescope (FAST, China). These projects include international collaborations, which allows us to compare how their curricula vary from their collaborators.

The aim of this conference paper is to review the curricula of the countries in the OECD, including China and South Africa, to identify whether the notion of Robotic Telescopes and Student Research (RTSR) exists in the regular science curriculum. In essence, it provides a preliminary insight into whether inquiry-based astronomy education can fit into the regular science curriculum. Section 1, provides a brief overview of Robotic Telescopes and Student Research. Following this, section 2, provides examples of where Robotic Telescopes and Student Research have been implemented in schools and their benefits. Section 3 highlights the complexity and brief history of Curriculum. In section 4, we present the core methodology for this review, while in sections $5 \& 6$, we present our analysis and results, respectively. Section 7 provides a brief discussion of our results and we conclude in Section 8.

\section{Robotic Telescopes, Student Research and Astronomy Education}

The extensive history and development of the field of Robotic Telescopes is beyond the scope of this paper. Furthermore, several authors with vastly more experience in the field have already provided in-depth reviews on several facets of Robotic Telescopes, incorporating Student Research (Genet, 2011), including the recent review of these instruments in education (Gomez and Fitzgerald, 2017), it is the field of education, which has yet to embrace and harness the power of Robotic Telescopes. The "authentic" nature of the use of Robotic Telescopes lends itself seamlessly to implementing IBL and "authentic science" in the context of the classroom, and by extension, student research. Students revel at the fact that they have been able to use real research-grade telescopes to obtain actual data. Although the exact role of ownership of the data in motivating students has yet to be determined, there is evidence that it is an 
important factor (Slater, 2018), this is echoed by McKinnon and Geissinger (2002), McKinnon et al. (2002) and Gould et al. (2006).

It is worthwhile highlighting the definition of Robotic Telescopes. Essentially, Robotic

Telescopes refers to telescopes which use hardware and software to control the telescope. Once telescopes are 'roboticised' users can remotely control them (Gomez and Fitzgerald, 2017).

Astronomy is commonly referred to as the "gateway science" (National Research Council, 2001) in the sense that it provides students with a conduit to get engaged with, and appreciate other sciences. This characteristic of astronomy was echoed in RTSRE 2017 keynote address by Timothy F. Slater, where he highlighted how it can be used as a vehicle to inspire students to appreciate science and encourage them to pursue science, rather than creating astronomers per se. This is illustrated in the recent work of Danaia et al. (2017) who reveal the significant positive changes in student perceptions of science after undertaking an astronomy education program.

In a sense, it should not be expected that 'Robotic Telescopes' should be found in the astronomy curriculum in the same manner that "Multimeter" would not be found within a physics curriculum necessarily. The telescope and the multimeter are both tools in the service of learning content and skills while driving motivation and interest. In a similar manner, 'Student Research' is unlikely to be found directly within the curriculum of many nations, but it is a theme that expresses itself in multiple guises, such as "Depth Studies" or "Problem-based Learning" or "Inquiry-based Learning" and can play small or large parts of the curricula. The question is how various curricula are tapping into Robotic Telescopes.

Another factor that should be noted is, despite the fact that we are seeing large-scale highly sophisticated telescopes/instruments for astronomical research; there is still a vast amount of research that can be conducted via small-scale telescopes. In fact, as highlighted by Querci and Querci (2000), some astronomical research is better suited to smaller telescope. This factor in and of itself warrants greater use of Robotic Telescopes in schools, especially given that astronomers do not have the time or resources to "study every square inch of the universe".

\section{Benefits of Robotic Telescopes and Student Research in Education}

It should be noted that while we highlight the term 'Robotic Telescopes', it is really about their 'Authentic use' in the curriculum, and by extension the classroom. Several studies, national reports and projects have highlighted the lack of interest in Science, Technology, Engineering and Mathematics (STEM) (Select Committee on Science and Technology (2002); Osborne et al. (2003); European Commission (2017); Tytler (2007); Tytler et al. (2008)).

Overall, the use of Robotic Telescopes in various educational contexts can be demarcated into two categories (Gomez and Fitzgerald, 2017), although projects can achieve both:

1. Those which provide engagement through aesthetic astronomical imaging

2. Those which provide authentic research through research-grade data collection involving astrometry, photometry or spectroscopy

We have listed a handful of the projects which implement authentic use of Robotic Telescopes in classrooms across the world, in different year levels from primary to high-school:

1. Universe in the Classroom (Roberts et al., 2018)

2. Charles Sturt University Remote Telescope Project (McKinnon, 2018)

3. Our Solar Siblings (Fitzgerald et al., 2018)

4. SPIRIT telescopes (Luckas and Gottschalk, 2018) 
5. SkyNet Observe (SkyNet, 2007) and SkyNet Junior Scholars (SkyNet, nd)

The above projects all possess similar over-arching aims: engaging students in STEM and providing students with authentic experiences in science. Evaluations of these projects has shown the positive effect they have on student learning in classrooms. However, although these projects exist, the question remains as to whether curricula are tapping into these resources. These projects as is the case of Our Solar Siblings ties directly into the Year 10 Australian Curriculum, International Baccalaureate and the Next Generation Science Standards.

Hollow $(2000,2009)$ show how authentic astronomical research using research-grade instruments engages gifted and high-achieving students who would otherwise be unenthused by the restrictive curriculum. The study by Roberts and Wassersug (2009), highlights the positive influence authentic research projects can have on school student's later science-related career choices. Furthermore, Gomez and Fitzgerald (2017), highlight how the use of Robotic Telescopes has led to authentic research and publications by school students. As a student going into tertiary education, whilst having a publication in a scientific journal to your name, would be a strong motivating factor to pursue science. And as teacher knowing that your students have contributed to the collective scientific knowledge of the Universe is priceless.

\section{The Curriculum}

The notion of curriculum as defined by its Latin root "course of race" is not new. Its first use in education dates back to the late 16th century (Hamilton, 2013). It was only in the early 20th century, inspired by the work of Frederick Taylor that John Franklin Bobbit produced his seminal works on the curriculum (Bobbit 1918, 1924). Bobbit's view was that curriculum provided teachers with procedures that would allow students to reach certain objectives. It was about creating efficiency and by extension, "standards of attainment".

The notion of standards ultimately made curriculum the sociopolitical statement it is today and an international endeavor (Pinar, 2013). As highlighted in the work of Burrill et al. (2015) and Pinar (2013), every country has their own approach to curriculum, although there are some commonalities. These standards influence what teachers can teach, although, some curricula intentionally offer broad statements, allowing teachers to put their own "twist" on what is covered. The amount of "twist" is, in essence, determined by the infamous time factor!

\section{Methodology}

At its core, this study is a policy research project (O'Toole and Beckett, 2014), which uses a mixed-methods approach to analyze curriculum documents. Curriculum documents were obtained from the Department of Education websites of OECD countries, and translated into English either by speakers of the native language or via Google Translate (C). The curriculum documents reviewed in this study were from countries in the OECD, which is a consortium of 35 countries across the world (OECD, 2016). As noted earlier, the study also included China and South Africa. These two countries are emerging nations in modern astronomy, ergo, they provide comparison points. Given that China has several different curricula, our study only focused on the school curriculum from Zhejiang. South Africa hosting the Square Kilometer Array (SKA) and China with its newly opened Five-hundred-meter Aperture Spherical radio Telescope (FAST), show that these countries are heavily investing in the development of astronomy.

\section{Analysis}

This study analyzed a total of 45 curricula from 28 OECD countries, including China and South Africa. This is due to the fact that curricula for the UK included three separate curricula for England, Scotland, Wales and Republic of Ireland, whilst the curricula for the USA included the states of Texas 
and California. In addition, the curriculum is different for each of the provinces in Canada.

The analysis involved extracting sections from the curriculum documents that explicitly addressed astronomy-related concepts. These sections were then analyzed using Leximancer, a text mining software application (Smith and Humphreys, 2006), to investigate if there were any instances of keywords related to Robotic Telescopes. The second level of the analysis involved identifying whether the extracted sections related to astronomy provided teachers with the flexibility to use Robotic Telescopes and/or Student Research to teach relevant knowledge/skills.

\section{Results}

The review of the 45 curricula revealed that astronomy-related topics were prevalent in at least two or more grades across the OECD countries, including China and South Africa. However, there was no mention of Robotic Telescopes, even though there were 19 instances of concepts related to telescopes and optics.

Some curricula intentionally provide broad open-ended statements as is the case of the Australian Curriculum. This allows the teacher to explore topics to whatever depth they see fit, whilst addressing the mandatory content. This would allow them to also incorporate Robotic Telescopes when teaching those topics.

Unsurprisingly curricula, which included astronomy as an elective, provided a better opportunity for seamlessly embedding learning via Robotic Telescopes and Student Research. An example of this is in the Victorian Certificate of Education (VCE) Physics Curriculum in Australia, which includes the Optional topic: What are stars? This opportunity could be due to the mere fact that electives were separate to the regular curriculum and often had separate time allocations. Whether these electives were taught by teachers with a background in Astronomy, could not be ascertained. However, this would play a vital role.

\section{Discussion}

Although this paper was concerned with a curriculum analysis, it is wise to connect the findings to the broader Astronomy Education Research. Specifically, whether the explicit presence of Robotic Telescopes in curricula enables long-term effective learning experiences for students? This question has been investigated by Slater (2018) who emphasizes that if telescopes are going to be used as a learning tool, then there needs to be a consistent use to ensure longstanding educational benefits. Based on this, if curriculum developers ever incorporate Robotic Telescopes into the regular science curriculum, they need to ensure that it is consistent and developmental, rather than a fleeting experience.

Secondly, we must ask whether the explicit mention of Robotic Telescopes in curricula is vital? Alternatively, it may be better to approach this more creatively by making curriculum statements broad and flexible to allow teachers to explore such topics. This approach, coupled with teacher education and active participation by the astronomy community, could potentially have long-standing effects. In addition, McLin (2011), highlights some of the barriers which are preventing high school teachers from integrating the use of Robotic Telescopes into their lessons - Standards \& Testing, Teacher Preparation and Access to Computer Resources.

Finally, we need to find a solution to alleviate the limited time teachers have to cover all topics. This will involve more of a political change and is beyond the scope of this study.

\section{Conclusion}

Robotic Telescopes have afforded the opportunity to anyone with a keen interest and curiosity to pursue astronomical research. Geographical locations, access to dark skies and sophisticated instruments are no longer limiting factors. However, despite the fact that the field of Robotic Telescopes has been active for decades, its integration into regular science curricula has been absent. 
Analysis of 45 curricula from 28 OECD countries, including China and South Africa, reveals that although there are occurrences of astronomy across Grades 1-12, in addition to astronomy in elective subjects, there is no explicit mention of Robotic Telescopes. Most of the curricula (with some exceptions) address topics in astronomy from a descriptive and conceptual perspective, focusing on the "what?" rather than the "why?" and "how?".

Though certain teachers who have the experience and interest might incorporate Robotic Telescope research in their astronomy classes, the majority who follow the "intended" curriculum will not consider using Robotic Telescopes in their classroom. We infer that time constraints and limited knowledge are key factors. This provides the impetus for astronomy educators and astronomers to be a lot more involved and active in the field of curriculum development.

\section{Acknowledgements}

I would like to thank the organizers of the RTSRE Conference for affording me the opportunity to present this work. In addition, my thanks to Dr. Michael Fitzgerald and Prof. David McKinnon of the Edith Cowan Institute for Education Research for their support during the RTSRE Conference and their helpful comments in preparing this paper. Most importantly, I would like to thank everyone who contributed to the translations of the curriculum documents.

\section{References}

Bobbitt, J. F. (1918). The curriculum. Houghton Mifflin, Boston.

Bobbitt, J. F. (1924). How to make a curriculum. Riverside Press, Boston.

Bruner, J. S. (1961). The act of discovery. Harvard educational review, 31:21-32.

Burrill, G., Lappan, G., and Gonulates, F. (2015). Curriculum and the Role of Research. In Cho, S. J., editor, The Proceedings of the 12th International Congress on Mathematical Education:
Intellectual and Attitudinal Challenges, pages 247-263. Springer.

Buxner, S. R. (2014). Exploring how research experiences for teachers changes their understandings of the nature of science and scientific inquiry. Journal of Astronomy and Earth Sciences Education, 1(1):53-68.

Chinn, C. A. and Hmelo-Silver, C. E. (2002). Authentic inquiry: Introduction to the special section. Science Education, 86(2):171-174.

Danaia, L., McKinnon, D. H., and Fitzgerald, M. (2017). Ideal pictures and actual perspectives of junior secondary school science: comparisons drawn from Australian students in an astronomy education programme. Research in Science \& Technological Education, 35(4):445-460.

Dewey, J. (1938). The theory of inquiry. New York: Holt, Rinehart \& Wiston.

European Commission (2017). Europe needs more scientists: Report by the high level group on increasing human resources for science and technology. Office for Official Publications of the European Communities.

Fitzgerald, M., Danaia, L., and McKinnon, D. H. (2017). Barriers inhibiting inquiry-based science teaching and potential solutions: perceptions of positively inclined early adopters. Research in Science Education, pages 1-24.

Fitzgerald, M., McKinnon, D., Danaia, L., Cutts, R., Salimpour, S., and Sacchi, M. (2018). Our Solar Siblings: A high school focused robotic telescope-based astronomy education project. In Fitzgerald, M. T., James, C. R., Buxner, S., and White, S., editors, Robotic Telescopes, Student Research, and Education Proceedings, volume 1(1), pages 217-231.

Genet, R. M. (2011). History of Robotic and Remotely Operated Telescopes: The Fairborn Observatory 1979-1989. In Conference Proceedings from Telescopes from Afar. 
Gomez, E. L. and Fitzgerald, M. T. (2017). Robotic telescopes in education. Astronomical Review, 13(1):28-68.

Gould, R., Dussault, M., and Sadler, P. (2006). What's Educational about Online Telescopes?: Evaluating 10 Years of MicroObservatory. Astronomy Education Review, 5(2):127-145.

Hamilton, D. (2013). Towards a Theory of Schooling (Routledge Revivals). Routledge.

Hollow, R. (2000). The student as scientist: Secondary student research projects in astronomy. Publications of the Astronomical Society of Australia, 17(2):162-167.

Hollow, R. (2009). Engaging gifted science students through astronomy. In Pasachoff, J. and Percy, J., editors, Teaching and learning astronomy: effective strategies for educators worldwide, pages 27-33. Cambridge University Press.

Luckas, P. and Gottschalk, K. (2018). The SPIRIT Telescope initiative: Engaging students in contemporary astronomy. In Fitzgerald, M. T., James, C. R., Buxner, S., and White, S., editors, Robotic Telescopes, Student Research, and Education Proceedings, volume 1(1), pages 201215.

McKinnon, D. (2018). The Charles Sturt University Remote Telescope Project. In Fitzgerald, M. T., James, C. R., Buxner, S., and White, S., editors, Robotic Telescopes, Student Research, and Education Proceedings, volume 1(1), pages 101-114.

McKinnon, D. and Geissinger, H. (2002). Interactive astronomy in elementary schools. Educational Technology \& Society, 5(1):124-128.

McKinnon, D. H., Geissinger, H., and Danaia, L. (2002). Helping them understand: Astronomy for Grades 5 and 6. Information Technology in Childhood Education Annual, 2002(1):263-275.

McLin, K. M. (2011). Using Robotic Telescopes to Teach STEM Skills: Undergraduate and High
School Students. In Presented at the Telescopes from Afar. Proceedings of the conference held 28 February - 3 March, 2011 at Waikoloa Beach, Hawai' $i$.

National Research Council (2001). Astronomy and astrophysics in the new millennium. National Academies Press.

OECD (2016). About the OECD. http://www.oecd. org/about/. Accessed 20 Feb 2016.

Osborne, J., Simon, S., and Collins, S. (2003). Attitudes towards science: A review of the literature and its implications. International journal of science education, 25(9):1049-1079.

O'Toole, J. and Beckett, D. (2014). Educational research: Creative thinking and doing. South Melbourne, Victoria, Australia: Oxford University Press, 2nd edition.

Pinar, W. F. (2013). International handbook of curriculum research. Routledge.

Querci, F. R. and Querci, M. (2000). Robotic telescopes and networks: New tools for education and science. Astrophysics and Space Science, 273(1-4):257-272.

Roberts, L. F. and Wassersug, R. J. (2009). Does doing scientific research in high school correlate with students staying in science? A half-century retrospective study. Research in Science Education, 39(2):251-256.

Roberts, S. E., Gomez, H., and Gomez, E. (2018). Universe in the Classroom: using robotic telescopes in primary schools. In Fitzgerald, M. T., James, C. R., Buxner, S., and White, S., editors, Robotic Telescopes, Student Research, and Education Proceedings, volume 1(1), pages 241255.

Sarkar, S. and Frazier, R. (2008). Place-based investigations and authentic inquiry. The Science Teacher, 75(2):29-33.

Select Committee on Science and Technology (2002). Science Education from 14 to 19. 
SkyNet (2007). SkyNet Project: OBSERVE.

SkyNet (n.d.). Discover the Universe With Skynet Junior Scholars.

Slater, T. (2018). To Telescope or Not To Telescope? In Fitzgerald, M. T., James, C. R., Buxner, S., and White, S., editors, Robotic Telescopes, Student Research, and Education Proceedings, volume $1(1)$, pages $41-45$.

Smith, A. E. and Humphreys, M. S. (2006). Evaluation of unsupervised semantic mapping of natural language with Leximancer concept mapping. $\mathrm{Be}$ havior research methods, 38(2):262-279.

Tytler, R. (2007). Re-imagining science education: Engaging students in science for Australia's future.

Tytler, R., Osborne, J., Williams, G., Tytler, K., and Cripps Clark, J. (2008). Engagement in STEM across the primary-secondary school transition: Opening up pathways. Australian Department of Education, Employment and Workplace Relations: Canberra.

van Eijck, M. and Roth, W.-M. (2009). Authentic science experiences as a vehicle to change students' orientations toward science and scientific career choices: Learning from the path followed by Brad. Cultural Studies of Science Education, 4(3):611-638.

Vygotsky, L. (1978). Mind in Society. The Development of Higher Psychological Processes.

Vygotsky, L., Hanfmann, E. E., and Vakar, G. E. (1962). Thought and language. 